\title{
The role of peripheral eosinophilia in diagnosing lung disorders: experience from a single pneumonological center
}

\author{
Justyna Fijolek, ${ }^{1}$ Elzbieta Wiatr, ${ }^{1}$ Dorota Piotrowska-Kownacka, ${ }^{2}$ Kazimierz Roszkowski-Sliz ${ }^{1}$ \\ ${ }^{\text {I}}$ The Third Department of Pneumonology and Oncology, National Tuberculosis and Lung Diseases Research Institute, \\ Warsaw \\ ${ }^{2}$ The First Department of Clinical Radiology, Independent Public Central Clinical Hospital of Medical University, Warsaw, \\ Poland
}

Background: Eosinophilia is rare but one of the important reasons to refer patients to pneumonological centers. Determining etiology of eosinophilia has practical implications for therapeutic intervention and disease prognosis. The study aimed to determine the role of peripheral eosinophilia in the diagnosis of lung disorders.

Methods: In this retrospective study were included 46 patients diagnosed with peripheral eosinophilia with coexisting respiratory symptoms and/or radiologically detected lung lesions. All patients underwent standard diagnostic procedures, including a detailed clinical history review, physical examination, routine laboratory tests with basal cardiological examinations, and serological tests to detect parasites and allergies. Other procedures carried out depended on the symptoms of each patient. The relation between eosinophil counts in the blood and patients' clinical manifestation was investigated to identify the degree of eosinophilia requiring immediate diagnostic procedures and treatment. Statistical analyses were performed using scientific computation libraries in the Python programming language, SciPy, v. 1.3.1. Briefly, the following tests were used: parametric Kruskal-Wallis $\mathrm{H}$ test, an independent t-test, ANOVA, the ShapiroWilk test, Fisher's and Chi-squared tests, and the Holm-Bonferroni method.

Results: Severe eosinophilia $(\geq 5,000$ cells/ $\mu$ l) was associated with extrapulmonary involvement and constitutional symptoms. Skin, heart, and pleural diseases were more frequent in these patients than in patients with mild or moderate eosinophilia ( $\mathrm{p}=0.010, \mathrm{p}=0.040$, and $\mathrm{p}=0.007$, respectively), and only these patients showed signs of kidney disease $(\mathrm{p}=0.006)$. Vasculitis was significantly more frequent in the severe eosinophilia group $(\mathrm{p}=0.048)$ than in the other two groups. In patients with moderate eosinophilia $(1,500-5,000$ cells/ $\mu \mathrm{l})$, extrapulmonary symptoms were less common, although signs of cardiac involvement were confirmed in $44 \%$ of subjects. In this group, vasculitis was the most commonly observed disease ( $42 \%$ of cases). Mild eosinophilia $(<1,500$ cells/ $\mu$ l) was mainly associated with airway disease. In this group, vasculitis and interstitial lung diseases were identified, but most were not typically connected with eosinophilia.

Conclusions: Identification of peripheral eosinophilia may essentially determine diagnostic procedures in patients with lung disorders and may be a useful indicator of disease etiology.

Key words: Eosinophilia; diagnostics; lung disorders.

Correspondence: Justyna Fijolek, MD, The Third Department of Pneumonology and Oncology, National Tuberculosis and Lung Diseases Research Institute, Plocka St. 26, 01-138 Warsaw, Poland. E-mail: jfijolek@op.pl

Contributions: JF, EW, conception and design; JF, DPK, analysis and interpretation of data; JF, manuscript drafting; JF, EW, KRS, critical revision of the manuscript. All the authors have read and approved the final version of the manuscript and agreed to be accountable for all aspects of the work.

Conflict of interest: The authors declare that they have no competing interests, and all authors confirm accuracy.

Availability of data and materials: The data that support the findings are available from the corresponding author on reasonable request.

Ethics approval and consent to participate: This was a retrospective analysis, obviating the need for approval from the local Ethics Committee, as routine procedures were used for clinical diagnosis and treatment of eosinophilia. 


\section{Introduction}

One of the reasons for referring patients to pneumonological centers is the identification of peripheral eosinophilia, which is defined as an increase in the number of eosinophils in peripheral blood exceeding 500 cells $/ \mu \mathrm{L}[1,2]$. Traditionally, eosinophilia has been classified by three stages: mild (exceeding the upper limit of normal, but fewer than 1,500 cells $/ \mu \mathrm{L}$ ), moderate (from 1,500 to 5,000 cells $/ \mu \mathrm{L}$ ), and severe (above 5,000 cells $/ \mu \mathrm{L}$ ) [3]. Eosinophilia can be transient, episodic, or persistent. Detection of elevated eosinophil counts in the blood on at least two occasions in an interval of time spanning more than one month is a necessary condition for diagnosing this white blood cell abnormality [1].

There are many causes of peripheral eosinophilia; the most common are allergic conditions, parasitic and fungal infections, as well as drug-related reactions. Rarer causes include vasculitis and primarily eosinophilic granulomatosis with polyangiitis (EGPA), though it can also accompany granulomatosis with polyangiitis (GPA) [4]. In these clinical situations, interstitial lung disease usually occurs in connection with eosinophilic infiltration. The most common disorders typically associated with eosinophilic infiltrations limited to the lung are acute and chronic eosinophilic pneumonia (AEP and CEP, respectively). The diagnosis of eosinophilic lung diseases primarily relies on characteristic clinical-imaging features and demonstration of alveolar eosinophilia defined by differential cell counts of at least $25 \%$ eosinophil cells in bronchoalveolar lavage fluid (BALF); in these cases, lung biopsy is generally unnecessary. In other conditions, however, when there is an absence of eosinophilia in BALF, lung biopsy is typically needed. Pathomorphological evidence of lung eosinophilia requires more extensive infiltration by eosinophils exceeding the upper limits of the normal physiological range $[5,6]$.

Determining the etiology of eosinophilic lung disorders has practical implications for therapeutic intervention and disease prognosis. Indeed, in most cases, oral corticosteroids are the key treatment, but in others, discontinuation of drug therapy or treatment of parasitic or fungal infections may be necessary. Additionally, there are many respiratory disorders that can be associated with mild eosinophilia, including asthma or organizing pneumonia (OP), but because their associations with eosinophilia is weak and usually do not affect the course of the disease, they are not considered to be eosinophilic lung diseases [7,8]. In these cases, there is usually no need for treatment of eosinophilia, although these patients, especially those with asthma, should still be monitored for the possible development of eosinophilic lung or systemic diseases. Patients with severe asthma and eosinophilia constitute a special group. In these cases biological drugs are the key treatment in reducing steroid use and improving the quality of life of the patients [9].

The purpose of present study was to analyze the role of peripheral eosinophilia in the diagnosis of lung disorders. We investigated the relation between eosinophil counts in the blood and patients' main clinical manifestation to identify the degree of eosinophilia requiring immediate diagnostic procedures and treatment. Additionally, we aimed to compare the differences in the identifiable causes of eosinophilia dictating working and final diagnoses.

\section{Methods}

The study was conducted within the statutory activity of the National Tuberculosis and Lung Diseases Research Institute, Warsaw, Poland; research task nr 7.28; Causes of eosinophilia in patients referred to the Pneumological Department. It was a retro- spective analysis, obviating the need for approval from the local Ethics Committee, as routine procedures were used for clinical diagnosis and treatment of eosinophilia. However, all procedures performed in the study were in accordance with the ethical standards of the institutional and national research committee, and with the tenets of the 1964 Declaration of Helsinki and its later amendments.

\section{Patients and study design}

The study included consecutive patients diagnosed with peripheral eosinophilia ( $>500$ cells $/ \mu \mathrm{L}$ ) with coexisting respiratory symptoms and/or radiological lung lesions detected at admission in the Department of Pneumonology of the National Tuberculosis and Lung Diseases Research Institute over the period from 2017 to 2019. There were 35 females (76.1\%) and 11 males (23.9\%), with a median age of 46.5 years (range: $19-76$ years). Suspected causes of eosinophilia were ANCA (antineutrophil cytoplasmic antibody)associated vasculitis (AAV) in 27 patients, CEP in six patients, allergic bronchopulmonary aspergillosis (ABPA) in five patients, asthma in four patients, lung tumor in two patients, hypersensitivity pneumonitis (HP) in one patient, and organizing pneumonia (OP) in one patient. Eosinophilia was considered to be mild when eosinophil count in the blood was 500-1,500 cells/ $\mu$, moderate at $1,500-5,000 \mathrm{cells} / \mu \mathrm{l}$, and severe at more than $5,000 \mathrm{cells} / \mu \mathrm{l}$ [3].

\section{Diagnostic testing}

All patients underwent standard diagnostic procedures involving detailed clinical history review, physical examination, routine laboratory testing in addition to quantification of C-reactive protein (CRP) and total immunoglobulin $\mathrm{E}$ (IgE) concentrations, Aspergillus serology and ANCA testing, as well as pulmonary function tests, and serological evaluation with enzyme-linked immunosorbent assays (ELISAs) in cases where parasitic infection was suspected (e.g., Toxocara or Trichinella). Concentrations of $\mathrm{CRP}>5 \mathrm{mg} / \mathrm{l}$ and total $\mathrm{IgE}>100 \mathrm{IU} / \mathrm{ml}$ were categorized as elevated. ANCA presence (inferred from myeloperoxidase (MPO) and proteinase-3 (PR3) levels) was determined by ELISA; a positive test was confirmed if levels were $\geq 20 \mathrm{RU} / \mathrm{ml}$ (relative units per milliliter). Aspergillus serology included quantification of the concentrations of specific IgE and IgG (immunoglobulin G); elevated levels were defined as $>0.35 \mathrm{kUA} / 1$ (kilo units of allergy-specific antibody per liter) and $>10 \mathrm{AU} / \mathrm{ml}$ (allergy units of antibody per milliliter), respectively. In all cases, lung imaging tests were performed, including chest radiography and computed tomography (CT), and all patients were evaluated for the presence of sinusitis. All patients underwent basal cardiological examinations, including electrocardiography (ECG) and echocardiography; natriuretic peptide-B (BNP) and troponin concentrations were quantified in serum. In all cases, bacterial and fungal cultures of sputum or bronchial fluid were performed. Additional tests, such as fiberoptic bronchoscopy (FOB), BALF, cardiac magnetic resonance (CMR), and Holter monitoring, were carried out depending on the symptoms presented by patients. In the presence of demonstrable lesions, biopsy procedures were performed when feasible and indicated. In cases of high eosinophilia and severe organ symptoms, diagnostic procedures were immediately initiated, without respecting the duration of time typically required for eosinophilia recognition ( $\geq 1$ month).

\section{Statistical analysis}

Statistical analyses were performed using scientific computation libraries in the Python programming language, SciPy, v. 1.3.1 (https://en.m.wikipedia.org/wiki/SciPy). For comparison of certain variables' median values, the non-parametric Kruskal-Wallis H test was used. An independent t-test was performed to compare the means of two numerical variables. Means of age were assessed 
using a one-way analysis of variance (ANOVA). Normal distribution was verified by the Shapiro-Wilk test. Additionally, we used Fisher's exact test for $2 \times 2$ nominal tests and Chi-squared tests to compare differences between expected and observed frequencies of one or more categories of nominal variables (differences in the distribution of clinical, laboratory, and radiological findings, and pulmonary function abnormalities depending on the severity and final etiology of eosinophilia). The statistical significance was set at $\mathrm{p}<0.05$. For multiple tests, the Holm-Bonferroni method was used.

\section{Results}

\section{Eosinophilia}

The mean eosinophil blood count was $4,198 \pm 4,081$ cells $/ \mu \mathrm{l}$ (range: $750-21,000$ cells $/ \mu 1$ ). Nine individuals $(19.6 \%)$ had mild $(500-1,500$ cells $/ \mu \mathrm{l}), 26(56.5 \%)$ had moderate $(1,500-5,000$ cells/ $\mu \mathrm{l})$, and $11(23.9 \%)$ had severe eosinophilia $(\geq 5,000 \mathrm{cells} / \mu \mathrm{l})$. The median duration of eosinophilia was eight weeks. Clinical characteristics of the study patients and a summary of the results of the diagnostic tests are described in Table 1.

\section{Clinical symptoms}

Patients were admitted to the hospital with a variety of clinical symptoms. The most common presentations were respiratory symptoms (cough and dyspnea were observed in $71.7 \%$ of patients) and symptoms associated with sinusitis/polyps (89.1\% of cases). Constitutional systemic signs presenting as fever and arthralgia affected one-third of patients. Among the organ manifestations, the most common (34.8\%) were cardiac symptoms (arrhythmia and breathlessness after exercise), while kidney disease was rarely observed (6.5\%). Statistical analysis comparing clinical manifestations depending on eosinophil blood counts showed the significantly more frequent occurrence of fever $(\mathrm{p}=0.023)$ and skin $(\mathrm{p}=0.010)$, heart $(\mathrm{p}=0.040)$, and kidney signs $(p=0.006)$ in the group of patients with severe eosinophilia compared with patients with moderate and mild eosinophilia. For the remaining clinical parameters, no statistical correlations between the groups were found, although arthralgia and neurological symptoms were more common in patients with severe eosinophilia than in patients with moderate and mild eosinophilia [(63.6\% versus $26.9 \%$ and $22.2 \%$ for arthralgia and $36.4 \%$ versus $11.5 \%$ and $0.0 \%$ for neurological symptoms; $\mathrm{p}=0.068$ and $\mathrm{p}=0.058$, respectively; Table 2, with reduced significance thresholds for 3 category tests (0.0166 0.025 0.05)].

\section{Laboratory investigations}

Comparisons of laboratory findings depending on the degree of eosinophilia are summarized in Table 2. Elevated concentrations of total $\mathrm{IgE}$ were significantly more common in the groups of patients with eosinophilia $\geq 1,500$ cells $/ \mu \mathrm{l}$ and $\geq 5,000$ cells $/ \mu \mathrm{l}$ compared with those with eosinophilia $<1,500$ cells $/ \mu l \quad(p=0.037)$, while the frequency of positive troponin test results was higher in the group of patients with severe eosinophilia $(\mathrm{p}=0.003)$ compared with those with mild or moderate eosinophilia. Elevated Aspergillus fumigatus-specific serum $\operatorname{IgE}$ and $\mathrm{IgG}$ antibodies were found only in patients with moderate eosinophilia.

\section{Imaging findings}

All patients except for three $(43 / 46 ; 93.5 \%)$ had abnormal chest CT scans. The coexistence of distinctly different lesions was observed in all patients. The most common lesions were thickening of the bronchial walls $(18 / 46 ; 39 \%)$, pulmonary consolidations
(16/46; 35\%), and ground-glass opacities (16/46; 35\%). We observed eight cases $(17.4 \%)$ of bronchiectasis filled by bronchial mucus, five (11\%) cases of pleural effusion, five (11\%) cases of mediastinal lymphadenopathy, four $(8.7 \%)$ cases of visible nodules, and two cases (4\%) of lung tumors (one case was imitated by lobe cirrhosis, and the second case was imitated by mucoid impaction). In 41/46 patients (89\%), sinusitis was confirmed by a CT scan. Abnormalities in echocardiography were found in $13 / 46$ patients $(28 \%)$, with the most common being a decrease in the left ventriculus ejection fraction (below 45\%) and pericardial effusion. CMR was performed in 30 patients; out of these, 16 patients $(53 \%)$ exhibited features of myocarditis. Analysis of radiological findings based on eosinophil blood counts showed that pleural effusion and echocardiography abnormalities were significantly more frequent in the group of patients with severe eosinophilia compared with those with moderate and mild eosinophilia ( $\mathrm{p}=0.007$ and $\mathrm{p}=0.026$, respectively; Table 2 ).

Table 1. Characteristics of $\mathbf{4 6}$ study patients.

\begin{tabular}{|c|c|}
\hline Parameter & Number (\%) \\
\hline Male & $11(23.9)$ \\
\hline Female & $35(76.1)$ \\
\hline Age (yrs, median) & 46.5 \\
\hline Smoking & $7(15.2)$ \\
\hline $\begin{array}{l}\text { Blood eosinophil count } \\
>500<1500 / \mu \mathrm{l} \\
\geq 1500<5000 / \mu \mathrm{l} \\
\geq 5000 / \mu \mathrm{l}\end{array}$ & $\begin{array}{c}9(19.6) \\
26(56.5) \\
11(23.9)\end{array}$ \\
\hline Time of duration of eosinophilia (weeks, median) & 8 \\
\hline $\begin{array}{l}\text { Clinical symptoms } \\
\text { Cough } \\
\text { Dyspnea } \\
\text { Sinus/polyps } \\
\text { Fever } \\
\text { Chest pain } \\
\text { Arthralgia } \\
\text { Skin } \\
\text { Gastrointestinal } \\
\text { Heart } \\
\text { Nerves } \\
\text { Kidney }\end{array}$ & $\begin{array}{l}33(71.7) \\
33(71.7) \\
41(89.1) \\
14(30.4) \\
12(26.1) \\
16(34.8) \\
10(21.7) \\
4(8.7) \\
16(34.8) \\
7(15.2) \\
3(6.5)\end{array}$ \\
\hline Hypoxemia $\left(\mathrm{PaO}_{2}<70 \mathrm{mmHg}\right)$ & $21(45.6)$ \\
\hline Total IgE elevated & $35(76.1)$ \\
\hline CRP elevated & $21(45.6)$ \\
\hline Airway obstruction & $23(51.1)$ \\
\hline Abnormal chest CT scan & $43(93.5)$ \\
\hline Abnormal cardiological tests (BNP/troponin/ECHO/Holter ECG) & $18(39.1)$ \\
\hline $\begin{array}{l}\text { Bronchoscopy } \\
\text { Inflammatory lesions } \\
\text { Purulent plugs } \\
\text { Erosions } \\
\text { Tumor } \\
\text { No lesions } \\
\text { BALF } \\
\text { Eosinophils in BALF elevated }\end{array}$ & $\begin{array}{l}36(78.3) \\
12(33.3) \\
7(19.4) \\
1(2.8) \\
1(2.8) \\
15(41.7) \\
19(52.8) \\
19(100)\end{array}$ \\
\hline $\begin{array}{l}\text { Biopsy } \\
\text { Positive }\end{array}$ & $\begin{array}{l}17(36.9) \\
11(64.7)\end{array}$ \\
\hline $\begin{array}{l}\text { Parasites test } \\
\text { Positive }\end{array}$ & $\begin{array}{l}46(100) \\
3(6.5)\end{array}$ \\
\hline
\end{tabular}

$\mathrm{PaO}_{2}$, partial pressure of oxygen; IgE, immunoglobulin E; CRP, C-reactive protein; CT, computed tomography; BNP, natriuretic peptide-B; ECG, electrocardiography; BALF, bronchoalveolar lavage fluid; ECHO-echocardiography. 
Table 2. Distribution of clinical, laboratory and radiological findings depending on the severity of peripheral eosinophil blood count.

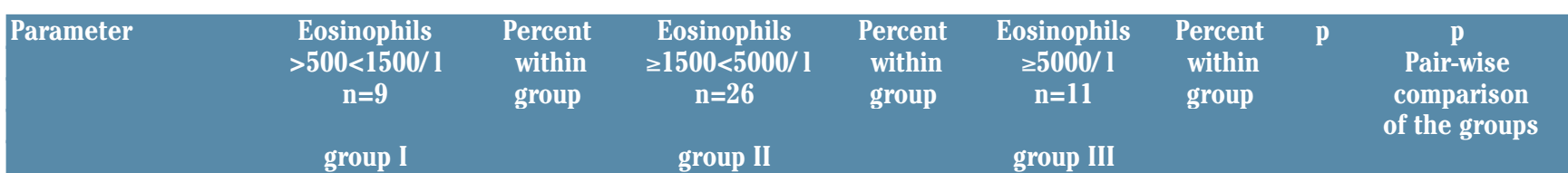

\begin{tabular}{|c|c|c|c|c|c|c|c|c|}
\hline Cough & 8 & 88.9 & 19 & 73.1 & 6 & 54.5 & 0.231 & - \\
\hline Dyspnea & 6 & 66.7 & 18 & 69.2 & 9 & 81.8 & 0.689 & - \\
\hline Fever & 2 & 22.2 & 5 & 19.2 & 7 & 63.6 & 0.023 & $\begin{array}{c}1.000 \text { (I-II) } \\
0.092 \text { (I-III) } \\
0.018 \text { (II-III) }\end{array}$ \\
\hline Arthralgia & 2 & 22.2 & 7 & 26.9 & 7 & 63.6 & 0.068 & - \\
\hline Sinus/polyps & 9 & 100 & 22 & 84.6 & 10 & 90.9 & 0.432 & - \\
\hline Chest pain & 1 & 11.1 & 7 & 26.9 & 4 & 36.4 & 0.436 & - \\
\hline Skin & 1 & 11.1 & 3 & 11.5 & 6 & 54.5 & 0.010 & $\begin{array}{c}1.000 \text { (I-II) } \\
0.070 \text { (I-III) } \\
\mathbf{0 . 0 1 1} \text { (II-III) }\end{array}$ \\
\hline Heart & 1 & 11.1 & 8 & 30.8 & 7 & 63.6 & 0.040 & $\begin{array}{c}0.391 \text { (I-II) } \\
0.028 \text { (I-III) } \\
0.080 \text { (II-III) }\end{array}$ \\
\hline Nerves & 0 & 0.0 & 3 & 11.5 & 4 & 36.4 & 0.058 & - \\
\hline Gastroinestinal & 0 & 0.0 & 3 & 11.5 & 1 & 9.1 & 0.570 & - \\
\hline kidney & 0 & 0.0 & 0 & 0.0 & 3 & 27.3 & $0.006^{*}$ & $\begin{array}{c}1.000 \text { (I-II) } \\
0.218 \text { (I-III) } \\
0.021 \text { (II-III) }\end{array}$ \\
\hline Total IgE elevated & 4 & 44.4 & 21 & 80.8 & 10 & 90.9 & 0.037 & $\begin{array}{c}0.081 \text { (I-II) } \\
0.049 \text { (I-III) } \\
0.646 \text { (II-III) }\end{array}$ \\
\hline
\end{tabular}

\section{Aspergillus specific}

0.

15.

$0.0 \quad 0.185$

IgE and IgG elevated

\begin{tabular}{|c|c|c|c|c|c|c|c|c|}
\hline CRP elevated & 4 & 44.4 & 10 & 38.5 & 7 & 63.6 & 0.371 & - \\
\hline BNP elevated & 0 & 0.0 & 9 & 34.6 & 5 & 45.4 & 0.070 & - \\
\hline troponin elevated & 0 & 0.0 & 3 & 11.5 & 6 & 54.5 & 0.003 & $\begin{array}{c}0.553(\mathrm{I}-\mathrm{II}) \\
\mathbf{0 . 0 1 4}(\mathrm{I}-\mathrm{III}) \\
\mathbf{0 . 0 1 1} \text { (II-III) }\end{array}$ \\
\hline ANCA presence & 2 & 22.2 & 2 & 7.7 & 1 & 9.1 & 0.471 & - \\
\hline Airway obstruction/severe & $6 / 0$ & $66.7 / 0$ & $13 / 1$ & $50.0 / 7.7$ & $4 / 2$ & $36.4 / 50.0$ & 0.369 & - \\
\hline $\mathrm{PaO}_{2}<70$ & 3 & 33.3 & 13 & 50.0 & 5 & 45.4 & 0.521 & - \\
\hline Thickening of the bronchial walls & 5 & 55.6 & 11 & 42.3 & 2 & 18.2 & 0.206 & - \\
\hline Pulmonary consolidations & 2 & 22.2 & 8 & 30.8 & 6 & 54.5 & 0.259 & - \\
\hline Ground-glass opacities & 3 & 33.3 & 10 & 38.5 & 3 & 27.3 & 0.804 & - \\
\hline Nodules & 1 & 11.1 & 1 & 3.8 & 2 & 18.2 & 0.353 & - \\
\hline Bronchiectasis/mucoid impaction & 3 & 33.3 & 5 & 19.2 & 0 & 0.0 & 0.137 & - \\
\hline Pleural effusion & 0 & 0.0 & 1 & 3.8 & 4 & 36.4 & $0.007^{*}$ & $\begin{array}{l}1.000 \text { (I-II) } \\
0.094 \text { (I-III) } \\
0.021 \text { (II-III) }\end{array}$ \\
\hline Tumor & 1 & 11.1 & 1 & 3.8 & 0 & 0.0 & 0.471 & - \\
\hline Lymphadenopathy & 0 & 0.0 & 2 & 7.7 & 3 & 27.3 & 0.110 & - \\
\hline Sinusitis & 9 & 100.0 & 22 & 84.6 & 10 & 90.9 & 0.432 & - \\
\hline Abnormalities in echocardiography & 0 & 0.0 & 7 & 26.9 & 6 & 54.5 & 0.026 & $\begin{array}{c}0.153 \text { (I-II) } \\
\mathbf{0 . 0 1 4} \text { (I-III) } \\
0.143 \text { (II-III) }\end{array}$ \\
\hline Abnormalities in CMR & 1 & 33.3 & 8 & 44.4 & 7 & 77.8 & 0.200 & - \\
\hline Parasites test positive & 0 & 0.0 & 1 & 3.8 & 2 & 18.2 & 0.184 & - \\
\hline
\end{tabular}

IgE, immunoglobulin E; IgG, immunoglobulin G; CRP, C-reactive protein; BNP, natriuretic peptide-B; ANCA, antineutrophil cytoplasmic antibody; Pa0 2 -partial pressure of oxygen; CT, computed tomography; CMR, cardiac magnetic resonance; *test should be repeated for larger data; the reduced significance thresholds for 3 category tests $(0.01660 .0250 .05)$ have been used. 


\section{Pulmonary function tests}

Airway obstruction determined by spirometry was observed in 23 $(50 \%)$ cases; in eight of these cases, the airway was mildly obstructed $(35 \%)$. This abnormality was observed with nearly the same frequency in patients with moderate eosinophilia $(13 / 26 ; 50 \%)$ as in patients with mild eosinophilia $(6 / 9 ; 66.7 \%)$, which was considerately more frequent than in patients with severe eosinophilia $(4 / 11 ; 36.4 \%)$. These differences between the groups were not statistically significant. Hypoxemia (defined in this study as $\mathrm{PaO}_{2}<70 \mathrm{mmHg}$ ) was detected in half of the patients, mainly in those with moderate and severe eosinophilia (13/26; 50\% and 5/11; 45\%, respectively; Table 2).

\section{FOB, BALF, and biopsy}

The procedures were performed using a Pentax fiberoptic bronchoscope EB 1970AK (Pentax Medical Co; Tokyo, Japan; distributor Varimed Co) and biopsy forceps (model HM /101-A$18 / 1200 \mathrm{~S})$. FOB was performed in $36 / 46$ patients $(78 \%)$; in 15 among them $(42 \%)$ no lesions were found. In 12 cases $(33 \%)$, inflammatory features of the bronchial tree were detected, which are described in detail in Table 1. There were no significant differences in these features between groups based on the degree of eosinophilia. Out of these 36 patients, BALF was performed in 19 (53\%): two of these patients belonged to the mild eosinophilia group (2/9 total), eleven of these patients belonged to the moderate eosinophilia group (11/26 total), and six of these patients belonged to the severe eosinophilia group (6/11 total). Eosinophil counts quantified from BALF ranged from $25 \%-85 \%$ of all cells. Biopsy was performed in $17 / 46$ patients $(37 \%)$; in most cases $(14 / 17$; $82 \%)$, these were bronchial mucosa ( 8 patients) or transbronchial lung biopsies (3 patients), but open lung biopsy was performed on two patients $(12 \%)$, and nasal biopsy was performed on one patient $(6 \%)$. Positive pathologies were confirmed in 11 of the 17 total biopsies performed (65\%), three of which were taken from patients with mild eosinophilia, whereas seven of which were taken from moderate eosinophilia patients, and one from a severe eosinophilia patient. As to the histopathological examination, in 4/8 cases of bronchial mucosa biopsy eosinophilic infiltrates predominated, which corresponded to CEP and/or EGPA diagnosis, and in 1/8 cases there was lung adenocarcinoma, while in the material from the transbronchial lung biopsies there were eosinophilic infiltrates consistent with a diagnosis of CEP ( 1 case), features of eosinophilic vasculitis ( 1 case), and features of OP (1 case). Other biopsy cases (open lung and nasal biopsy) showed pattern typical for GPA. No significant differences in the frequency of positive biopsy results were observed among the groups based on the degree of peripheral eosinophilia $(\mathrm{p}=0.104)$.

\section{Microbial cultures}

Positive bacterial cultures were found in 8/46 (17\%) cases (one case with mild eosinophilia, six cases with moderate eosinophilia, and one case with severe eosinophilia), while positive fungal cultures were detected only in $4 / 46(9 \%)$ patients, all of whom had moderate eosinophilia. There was no significant difference between the groups based on the degree of peripheral eosinophilia $(p=0.185)$.

\section{Parasitology}

Positive parasitic serologic tests (assessed by ELISAs) for toxocariasis were observed in $3 / 46$ cases $(6.5 \%)$ : one case in a patient with moderate eosinophilia, and two cases in patients with severe eosinophilia. There was no significant difference in the rate of infection among the groups based on the degree of eosinophilia $(\mathrm{p}=0.184)$.

\section{Diagnoses}

In most patients (23/46; 50\%), AAV was identified (21/23 with EGPA, 2/23 with GPA). In 8/46 (17.4\%) patients, different interstitial lung diseases (ILDs) were identified, six of which were determined to be CEP and two of which were determined to be OP. In $8 / 46$ patients $(17.4 \%)$, asthma was found to be the sole cause of peripheral eosinophilia. In $7 / 46$ cases $(15.2 \%)$, allergic diseases caused by external factors (ADEF) were recognized: ABPA in four patients, and parasitic infection in three patients. Patients with AAV were significantly younger $(\mathrm{p}=0.025)$ compared with those with other diagnoses (ILDs, asthma, ADEF), but no statistical difference was observed between males and females $(p=0.615)$. The median eosinophil blood count did not differ significantly in individual disease groups (AAV, ILDs, asthma, and ADEF) $(\mathrm{p}=0.100)$, but it was the highest in AAV patients. Similarly, no significant difference was found in median total IgE concentration based on individual diagnoses $(p=0.190)$. AAV was frequently identified in the group of patients with severe eosinophilia $(p=0.048)$ compared with those with moderate or mild eosinophilia (Table 3, reduced significance thresholds for 3 category tests: $0.0166 \quad 0.0250 .05$ ) The results of the comparative analysis of the patient groups based on the final etiology are presented in Table 4. In 27/46 patients (58.7\%), final causes of eosinophilia matched those suspected initially at the time of referral, while in $19 / 46$ cases $(41.3 \%)$, the etiological causes determined from the final diagnoses were inconsistent with the initially suspected causes of eosinophilia (Table 5). Interestingly, the final diagnosis of AAV was the most consistent cause among the patients' initial suspected diagnoses, compared to other diseases ( $\mathrm{p}=0.001$; Table 4 , significant thresholds for 6 comparisons with values: 0.00830 .010 .01250 .01660 .0250 .05 ).

Table 3. The relation between the value of peripheral eosinophilia and final diagnoses in study patients.

\begin{tabular}{|c|c|c|c|c|c|c|c|c|}
\hline Final diagnosis & $\begin{array}{c}\text { Eosinophils } \\
>500<1500 / 1 \\
n=9 \\
\text { group I }\end{array}$ & $\begin{array}{l}\text { Percent } \\
\text { within } \\
\text { group }\end{array}$ & $\begin{array}{c}\text { Eosinophils } \\
\geq 1500<5000 / 1 \\
\mathrm{n}=26 \\
\text { group II }\end{array}$ & $\begin{array}{l}\text { Percent } \\
\text { within } \\
\text { group }\end{array}$ & $\begin{array}{c}\text { Eosinophils } \\
\geq 5000 / 1 \\
n=11\end{array}$ & $\begin{array}{l}\text { Percent } \\
\text { within } \\
\text { group }\end{array}$ & $\mathbf{p}$ & $\begin{array}{c}\text { P } \\
\text { Pair-wise } \\
\text { comparison } \\
\text { of the groups }\end{array}$ \\
\hline AAV & 3 & 33.33 & 11 & 42.31 & 9 & 81.82 & 0.048 & $\begin{array}{l}0.712(\mathrm{I}-\mathrm{II}) \\
0.065(\mathrm{I}-\mathrm{III}) \\
0.036(\mathrm{II}-\mathrm{III})\end{array}$ \\
\hline ILD & 3 & 33.33 & 5 & 19.23 & 0 & 0.00 & 0.137 & - \\
\hline Asthma & 3 & 33.33 & 5 & 19.23 & 0 & 0.00 & 0.137 & - \\
\hline $\mathrm{ADEF}$ & 0 & 0.00 & 5 & 19.23 & 2 & 18.18 & 0.365 & - \\
\hline
\end{tabular}

AAV, antineutrophil cytoplasmic antibody associated vasculitis; ILD, interstitial lung disease; ADEF, allergic diseases caused by external factors; the reduced significance thresholds for 3 category tests ( 0.01660 .0250 .05 ) have been used. 


\section{Discussion}

Our study demonstrates that the severity of peripheral eosinophilia may be an essential predictor of diagnostic procedures in patients with lung disorders. Lung diseases associated with marked peripheral blood or tissue eosinophilia are unusual and are nearly always clinically significant, providing important information to guide diagnosis. Our study indicates that eosinophilia $\geq 5,000$ cells $/ \mu \mathrm{L}$ requires rapid diagnostics to allow for urgent treatment due to the possibility of organ involvement and the dangers of irreversible organ injury. The diagnostics should be primarily directed to identify the possibility of AAV (with cardiological and nephrological tests), but tests for parasites should also be conducted to exclude the possibility of parasitic infection, which would require different treatment. Eosinophilia with counts of 1,5005,000 cells $/ \mu \mathrm{L}$ can reflect various conditions; therefore, in these cases, extensive diagnostic testing should be performed to search for various causes of eosinophilia, with a particular focus on identifying vasculitis, but also other eosinophilic lung diseases, as well as allergic and airway diseases and parasitic infections. Eosinophilia with counts $<1,500$ cells/ $\mu$ is usually mild and mainly connected with symptoms of airway disease, but the need for more extensive diagnostics should not be ignored, particularly when lung and/or other organ lesions are present.

Severe eosinophilia with counts $\geq 5,000$ cells $/ \mu 1$, which was exhibited by 11 patients $(24 \%)$ in our study, was associated with extrapulmonary involvement and constitutional symptoms. Patients mainly reported pulmonary symptoms (71.7\%), but simple diagnostic tests to quantify CRP, troponin, or BNP, and echocardiography revealed a variety of abnormalities. Skin and heart diseases were significantly more frequent $(\mathrm{p}=0.010$ and $\mathrm{p}=0.040$, respectively), and only this group - compared to those with mild or moderate eosinophilia - displayed signs of kidney disease $(p=0.006)$, mainly manifesting as proteinuria. Similarly, neurological symptoms were more frequent in this group $36.4 \%$ versus $11.5 \%$ and $0.0 \%$ of patients with moderate and mild eosinophilia, respectively). A common feature of these patients was inflammatory syndrome manifesting as fever $(\mathrm{p}=0.023)$, as well as CRP elevation (63.6\% versus $44.4 \%$ and $38.5 \%$ of patients with moderate and mild eosinophilia, respectively). In this group, abnormalities in echocardiography and increased troponin concentrations occurred significantly more frequently $(\mathrm{p}=0.026$ and $\mathrm{p}=0.003$, respectively), and positive results of CMR were the most common $(78 \%)$ compared to the groups with mild and moderate eosinophilia. In radiological studies, we predominantly observed parenchymal infiltrations, but pleural effusion was significantly more often detected in this group $(p=0.007)$ compared to moderate and mild eosinophilia groups. Patients with severe eosinophilia reported shortness of breath more often than cough, but airway obstruction was less common, and reversibility was observed significantly more frequently in this group only $(\mathrm{p}=0.013)$ compared to moderate and mild eosinophilia groups. Patients in the severe eosinophilia group, compared to those with mild or moderate eosinophilia, were predominantly diagnosed with AAV (9/11; $\mathrm{p}=0.048$ ), although in two out of 11 cases, parasitic infections (toxocariasis) were found. This result was surprising because Toxocara infection usually does not cause eosinophilia $\geq 5,000$ cells $/ \mu 1$ $[10,11]$.

Patients with moderate eosinophilia comprised the largest group in our study (26/46 patients; $56.5 \%$ ). They reported dyspnea

Table 4. Comparative characteristics of the study patients depending on the final etiology

\begin{tabular}{|c|c|c|c|c|c|}
\hline Parameter (n) & $\begin{array}{c}\text { AAV }(\mathrm{N}=23) \\
\text { n }(\%)\end{array}$ & $\begin{array}{c}\text { ILD }(\mathrm{N}=8) \\
\text { n (\%) }\end{array}$ & $\begin{array}{c}\text { Asthma }(\mathrm{N}=8) \\
\text { n (\%) }\end{array}$ & $\begin{array}{c}\text { ADEF }(\mathrm{N}=7) \\
\text { n }(\%)\end{array}$ & $\mathbf{p}$ \\
\hline $\begin{array}{l}\text { Male } \\
\text { Female }\end{array}$ & $\begin{array}{c}6(26.1) \\
17(73.9)\end{array}$ & $\begin{array}{l}3(37.5) \\
5(62.5)\end{array}$ & $\begin{array}{l}1(12.5) \\
7(87.5)\end{array}$ & $\begin{array}{l}1(14.3) \\
6(85.7)\end{array}$ & 0.615 \\
\hline Age (yrs, mean) & $41.39 \pm 14.0$ & $50.75 \pm 15.8$ & $53.88 \pm 17.7$ & $61.14 \pm 13.6$ & 0.025 \\
\hline Upper respiratory symptoms (sinus/polyps) & $22(95.6)$ & $7(87.5)$ & $6(75.0)$ & $6(85.7)$ & 0.429 \\
\hline Lower respiratory symptoms (cough and/or dyspnea) & $21(91.3)$ & $8(100.0)$ & $8(100.0)$ & $7(100.0)$ & 0.554 \\
\hline General symptoms (fever and/or arthralgia) & $16(69.6)$ & $2(25.0)$ & $2(25.0)$ & $1(14.3)$ & 0.013 \\
\hline Extrapulmonary organ symptoms & $21(91.3)$ & $0(0.0)$ & $1(12.5)$ & $0(0.0)$ & $<0.001$ \\
\hline Airway obstruction & $14(60.9)$ & $1(14.3)$ & $5(62.5)$ & $3(42.8)$ & 0.152 \\
\hline Respiratory failure $\left(\mathrm{PaO}_{2}<60 \mathrm{mmHg}\right)$ & $3(13.0)$ & $1(12.5)$ & $0(0.0)$ & $1(14.3)$ & 0.754 \\
\hline CT scan abnormalities & $23(100.0)$ & $8(100.0)$ & $5(62.5)$ & $7(100.0)$ & 0.002 \\
\hline Mean blood eosinophil count (range) & $\begin{array}{l}5816 \pm 5781 \\
(750-21000)\end{array}$ & $2254 \pm 1451(1400-4600)$ & $\begin{array}{c}1984 \pm 877 \\
(920-3980)\end{array}$ & $\begin{array}{c}3632 \pm 2436 \\
(1083-7600)\end{array}$ & 0.100 \\
\hline IgE elevated & $19(82.6)$ & $6(75.0)$ & $4(50.0)$ & $6(85.7)$ & 0.273 \\
\hline mean & $912 \pm 1768$ & $425 \pm 400$ & $366 \pm 506$ & $1889 \pm 1481$ & 0.184 \\
\hline CRP elevated & $13(56.5)$ & $5(62.5)$ & $2(25.0)$ & $1(14.3)$ & 0.104 \\
\hline mean & $47.7 \pm 64.6$ & $19.7 \pm 28.4$ & $7.7 \pm 14.2$ & $6.8 \pm 8.2$ & 0.113 \\
\hline BNP elevated & $11(47.8)$ & $0(0.0)$ & $2(25.0)$ & $1(14.3)$ & 0.051 \\
\hline Troponin elevated & $8(34.8)$ & $0(0.0)$ & $1(12.5)$ & $0(0.0)$ & 0.063 \\
\hline ANCA presence & $5(21.7)$ & $0(0.0)$ & $0(0.0)$ & $0(0.0)$ & 0.132 \\
\hline Positive cultures (bacterial and/or fungal) & $5(21.7)$ & $0(0.0)$ & $2(25.0)$ & $3(42.9)$ & 0.250 \\
\hline Positive biopsy & $11(47.8)$ & $4(50.0)$ & $1(12.5)$ & $1(14.3)$ & 0.148 \\
\hline Accordance with the initial diagnosis & $20(86.9)$ & $2(25.0)$ & $2(25.0)$ & $3(42.9)$ & 0.001 \\
\hline
\end{tabular}

$\mathrm{PaO}_{2}$, partial pressure of oxygen; CT, computed tomography; IgE, immunoglobulin E; CRP, C-reactive protein; BNP, natriuretic peptide B; ANCA, antineutrophil cytoplasmic antibody; AAV, antineutrophil cytoplasmic antibody associated vasculitis; ILD, interstitial lung disease; ADEF, allergic diseases caused by external factors; the significant thresholds for 6 comparisons with values: 0.0083 0.01 0.0125 0.01660 .0250 .05 have been used. 
and cough with a similar frequency $(70 \%)$, but extrapulmonary symptoms were less common compared to the patients in the severe eosinophilia group. Twenty-seven percent of the patients with moderate eosinophilia complained of chest pain, and $31 \%$ demonstrated signs of cardiac involvement, which was confirmed by CMR in $44 \%$ and by BNP elevation in $35 \%$ of cases. Radiological examinations revealed bronchial changes in more than half of the patients (thickening of the bronchial walls and/or bronchiectasis), while in almost $40 \%$ of patients, pulmonary consolidations and ground-glass opacities were found. Airway obstruction was present in $50 \%$ of patients, and up to $81 \%$ had increased concentrations of total IgE. In the moderate eosinophilia group, while various diseases were recognized, AAV was the predominant diagnosis in $42 \%$ of patients. In the remaining patients, ILD, asthma, and allergic diseases (including ABPA and parasitic infection) were observed with the same frequency (about $20 \%$ of cases for each disease).

Patients with mild eosinophilia constituted the smallest group in our study $(9 / 46 ; 19.6 \%)$ and mainly complained of cough $(89 \%)$, and all had sinus involvement. Only $11 \%$ of these patients presented symptoms due to the involvement of other organs. CT scans predominantly revealed bronchial changes (thickening of the bronchial walls in $50 \%$ of patients and bronchiectasis in $33 \%$ of patients), which were more common compared to the groups with a higher degree of eosinophilia. In patients with mild eosinophilia, only two of all the radiological images $(2 / 16 ; 12.5 \%)$ showed pulmonary consolidations, and three images $(3 / 16 ; 19 \%)$ revealed ground-glass opacities. None of these patients had serological markers associated with cardiac involvement or echocardiography abnormalities, and features of cardiac inflammation revealed by CMR were found in only one case. In these patients, airway obstructions were detected more frequently compared to other groups $(66.7 \%)$, and only in these patients, irreversible obstructions were observed. In this group, AAV, ILD, and asthma were identified as the sole cause of eosinophilia with equal frequency (each in $1 / 3$ cases).

A few reports have investigated the association between levels of blood eosinophils and organ manifestations. Okada et al. [12], in their retrospective analysis, showed that severe eosinophilia, defined as $>10,000$ cells $/ \mu$ (found in only $6 \%$ of patients), was associated namely with EGPA, non-episodic angioedema with eosinophilia (NEAE), and mono-organ involvement associated with eosinophilia, while cases of less severe eosinophilia $(2,000$ 10,000 cells $/ \mu \mathrm{L}$ ) tended to result in more differential diagnoses, requiring initial exclusion of the possibility of skin disease, drug reactions, and solid/hematological tumors. In their study, bronchial asthma was rarely connected with eosinophilia $>2,000$ cells $/ \mu \mathrm{l}(3 \%$ of cases), which is in opposition with our own results, as we observed that asthma was the sole cause of almost $20 \%$ of cases of moderate eosinophilia. Sade et al. [13] analyzed 100 patients hospitalized in a tertiary urban hospital and found no correlation between the severity of eosinophilia and the type or severity of the symptoms.

An interesting study by Bjerrum et al. [14] investigated records of two groups of patients with normal and elevated levels of blood eosinophils and analyzed their subsequent risk of developing disorders with organ involvement. Compared with the median baseline eosinophil count of $160 \mathrm{cells} / \mu \mathrm{l}$, risks for organ disease (cardiac, skin, neurological, gastrointestinal, or respiratory) were increased when eosinophil counts were both above and below the values defining eosinophilia. The authors concluded that the risk for organ damage due to eosinophilia did not increase in direct proportion with elevated cell counts and that normal or even low eosinophil counts did not rule out possible risks of adverse organ effects of these cells [14]. These results can partially be explained by the fact that blood eosinophil counts may not be representative of the degree of eosinophilic tissue infiltration [1]. The second reason may be differences in the degree of eosinophil activation. Studies of members of an asymptomatic family with hypereosinophilia (HES) $(2,000-5,000$ cells/ $\mu$ l) showed that they exhibited a relative lack of eosinophil activation compared with those with nonfamilial HES [15]. Our study indicates that the severity of eosinophilia essentially correlates with the severity of symptoms. Eosinophilia $\geq 5,000$ cells $/ \mu$ l was significantly associated with cardiac and skin involvement, and signs of kidney and pleural diseases were present only in this group. Echocardiogram abnormalities and increases in serum cardiac markers were found only in patients with eosinophilia $\geq 1,500$ cells $/ \mu 1$, but their frequency was significantly more common in those with eosinophilia $\geq 5,000$ cells $/ \mu$ l. In contrast, eosinophilia $<1,500$ cells $/ \mu$ was mainly associated with symptoms of airway disease, and, in any of these patients, cardiac markers were detected. Admittedly, up

Table 5. Comparison of differences in the identifiable causes of eosinophilia dictating initial working and final diagnoses in study patients.

\begin{tabular}{|c|c|c|c|}
\hline & $\begin{array}{l}\text { Initial working } \\
\text { diagnosis (n) }\end{array}$ & $\begin{array}{l}\text { Final diagnosis in } \\
\text { accordance with the initial } \\
\text { diagnosis (n) }\end{array}$ & $\begin{array}{l}\text { Final diagnosis inconsistent } \\
\text { with the initial diagnosis (n) }\end{array}$ \\
\hline AAV & 27 & 20 & $\begin{array}{c}7 \\
{[\text { CEP-4, asthma-3] }}\end{array}$ \\
\hline CEP & 6 & 1 & $\begin{array}{c}5 \\
\text { [EGPA-2, parasites-1, OP-1, asthma-1] }\end{array}$ \\
\hline $\mathrm{ABPA}$ & 5 & 3 & [CEP-1, asthma with mucoid impaction-1] \\
\hline Asthma & 4 & 2 & $\begin{array}{c}2 \\
\text { [Parasites] }\end{array}$ \\
\hline Lung tumor & 2 & 0 & $\begin{array}{c}2 \\
\text { [Asthma with lobe lung cirrhosis-1, ABPA-1] }\end{array}$ \\
\hline HP & 1 & 0 & $\begin{array}{c}1 \\
{[\mathrm{AAV}(\mathrm{EGPA})-1]}\end{array}$ \\
\hline $\begin{array}{l}\text { OP } \\
\text { Total } n\end{array}$ & $\begin{array}{c}1 \\
46(100 \%)\end{array}$ & $\begin{array}{c}1 \\
27(58.7 \%)\end{array}$ & $\begin{array}{c}0 \\
19(41.3 \%)\end{array}$ \\
\hline
\end{tabular}

AAV, antineutrophil cytoplasmic antibody associated vasculitis; CEP, chronic eosinophilic pneumoniae; EGPA, eosinophilic granulomatosis with polyangiitis; ABPA, allergic bronchopulmonary aspergillosis; HP, hypersensitivity pneumonitis; OP, organizing pneumonia. 
to $33.3 \%$ of patients with mild eosinophilia were diagnosed with AAV, as were $33.3 \%$ of those with ILD, but the majority of these diseases were not typically connected with pulmonary eosinophilia (2/3 cases of GPA and $2 / 3$ cases of OP).

Another aspect of this study concerned the analysis of causes of eosinophilia in our patient groups and comparisons between initial suspected and final diagnoses. In this group of 46 patients, the most frequent cause of eosinophilia was AAV (diagnosed in half of the cases), which was highly representative of the group with eosinophilia $\geq 5,000$ cells $/ \mu$, followed by ILD, which was found in eight cases $(17.5 \%)$; asthma was the sole cause of eosinophilia in eight cases as well $(17.5 \%)$, and allergic pulmonary diseases (including ABPA or parasitic infections) were identified in seven patients (15\%). These results differ from other studies. The probable reason for these differences was discrepancies between the pneumonological profiles of our patients and our hospital characteristics. For example, in the study by Lombardi et al. [16], in 1,862 cases diagnosed due to eosinophilia, allergic disorders were largely predominant ( $80 \%$ of cases), while AAV and CEP were much rarer and were found only in $0.16 \%$ and $0.05 \%$ of cases, respectively. Similarly, in a report by Sade et al. [13], which analyzed 100 hospitalized patients, allergic or atopic diseases were the most frequent cause of eosinophilia. EGPA, in their study, was identified in only $4 \%$ of cases (compared with $21 / 46$, or $45.6 \%$, in our study), while the frequency of parasitic infections they reported $(5 \%)$ was similar to our own results $(3 / 46 ; 6.5 \%)$.

Comparative analysis of initial and final diagnoses in our patients revealed that in $27 / 46$ patients $(58.7 \%)$, there was no discrepancy between the final etiologies of eosinophilia determined after testing and the initial working diagnoses, while in 19 cases $(41.3 \%)$, the final diagnoses were inconsistent with the initial suspected causes of eosinophilia, and other disorders were ultimately identified. These findings highlight the difficulties in diagnosing eosinophilic lung diseases, which can overlap with various other pulmonary and/or respiratory disorders. For example, before the onset of manifestations of vasculitis, it may be difficult to distinguish EGPA from eosinophilic asthma, whereas CEP, which may be confused with EGPA, has no vasculitic and extrapulmonary signs, and thus remains an exclusionary diagnosis. In our study, among the six patients referred due to CEP suspicion, a diagnostic confirmation was achieved in only one patient, while in the next five cases, other diseases were recognized (EGPA in two cases, one case of parasitic infection, one case of OP, and one case where asthma was the sole cause of eosinophilia). In all our patients who were ultimately diagnosed with a parasitic infection, the initial admission was for suspected asthma or CEP, not parasitosis. Interestingly, although overlap between the initial suspected and final confirmed cause of eosinophilia was observed in roughly $60 \%$ of cases, AAV was most accurately recognized from the onset compared to other diseases $(\mathrm{p}=0.001)$.

In summary, our study indicates that evaluation of eosinophilia in patients with lung disorders should be based on its severity, the symptoms, and the results of diagnostic tests. ECG and serological cardiac tests are important and should be performed in all patients diagnosed with eosinophilia, but mainly in those cases where eosinophilia $\geq 1,500$ cells $/ \mu$ l and should be mandatory in those cases where counts $\geq 5,000$ cells/ $\mu$ l. CMR seems to be more sensitive than the techniques used in the above-mentioned investigations and in agreement with current recommendations [17]; therefore, it should be performed even in asymptomatic patients diagnosed with eosinophilia. This method, through its great versatility, gives valuable information not only about specific cardiac inflammation, but also provides information about cardiac function, type of fibrosis, vascular integrity, and thrombosis that may significantly aid treatment decisions and improve prognosis [18-20]. In our study, myocarditis in CMR was generally detectable in up to $53 \%$ of patients, but the highest percentage of positive CMR results was observed in cases with eosinophilia $\geq 5,000$ cells $/ \mu$ l $(78 \%)$, followed by cases with eosinophil counts between 1,500-5,000 cells/ $\mu 1(\approx 45 \%)$. In our study, chest CT scans revealed abnormalities in $93 \%$ of cases, and the type of lesions varied depending on the severity of eosinophilia. In patients with eosinophilia $\geq 5,000 / \mu 1$, parenchymal infiltrations were predominant, while in cases of eosinophilia $<1,500$ cells/ $\mu 1$, bronchial lesions were the most common findings. Airway obstruction detected by spirometry was found in half of our patients and was most frequently observed in the group with eosinophil counts $<1,500$ cells/ $\mu 1$ (66.7\%). In all cases of eosinophilia, serologic tests for parasites should be performed to exclude the possibility of parasitic infection requiring other treatments [16,21,22].

Our study is the first clinical study to analyze the role of peripheral eosinophilia in diagnosing lung disorders, but it does have some limitations. First, the study was retrospective and included only hospitalized patients who probably had more severe symptoms and a greater degree of eosinophilia compared with what one would typically expect to see in outpatient diagnosis, which could have affected the results. Therefore, it would be advisable to include patients who are managed in primary care also, in the cohort of future research, to obtain more generalizable results. Second, some patients received short-term oral glucocorticoids, which could have contributed to a reduction in the degree or severity of eosinophilia. A potential confounding effect of steroids should be a matter of interest in future studies. Finally, the small sample size provides preliminary results requiring further investigation and confirmation through larger prospective studies. An increase in the number of patients could provide more accurate and reliable statistical results.

\section{Conclusions}

Peripheral eosinophilia is one of the important reasons to refer patients to pneumonological centers. Eosinophilia $\geq 5,000$ cells $/ \mu 1$ is significantly associated with extrapulmonary organ involvement and requires immediate diagnostic procedures, primarily to identify the possibility of vasculitis, with a particular emphasis on basic cardiological tests, which should also be performed in patients with a lesser, but marked, degree of eosinophilia. Eosinophilia with counts of $1,500-5,000$ cells $/ \mu 1$ is associated with a wide variety of conditions; therefore, in these cases, extensive diagnostic testing should be performed to identify the cause of eosinophilia, with particular emphasis on identifying the possibility of vasculitis, but also other eosinophilic lung diseases, as well as allergy and airway diseases. While mild eosinophilia with counts $<1,500$ cells/ $\mu 1$ is mainly associated with symptoms of airway disease, one must not rule out the need for more extensive diagnostics, particularly when lung and/or organ lesions are present. Patients with mild eosinophilia without signs of organ damage should be monitored for development of eosinophilic lung or systemic diseases, especially when they suffer from asthma, as asthmatic patients experience EGPA even 34 times more frequently than those in the general population $[23,24]$. In any case, parasitic infections should be ruled out to avoid over-prescribing glucocorticoids, which is the key therapy used to treat most eosinophilic lung diseases. While vasculitis, especially EGPA, is classified as a rheumatological disease, it was the most common cause of eosinophilia in our study. Although the overlap of first and final etiology of eosinophilia affected only about $60 \%$ of cases, AAV was most accurately recognized. The degree of peripheral eosinophilia may essentially deter- 
mine the diagnostic procedures in patients with lung disorders and may be a strong indicator of disease etiology.

\section{Acknowledgements}

The authors acknowledge colleagues not included in the author list for taking care of study patients, and the professional English Editing Service for English language revision of the manuscript.

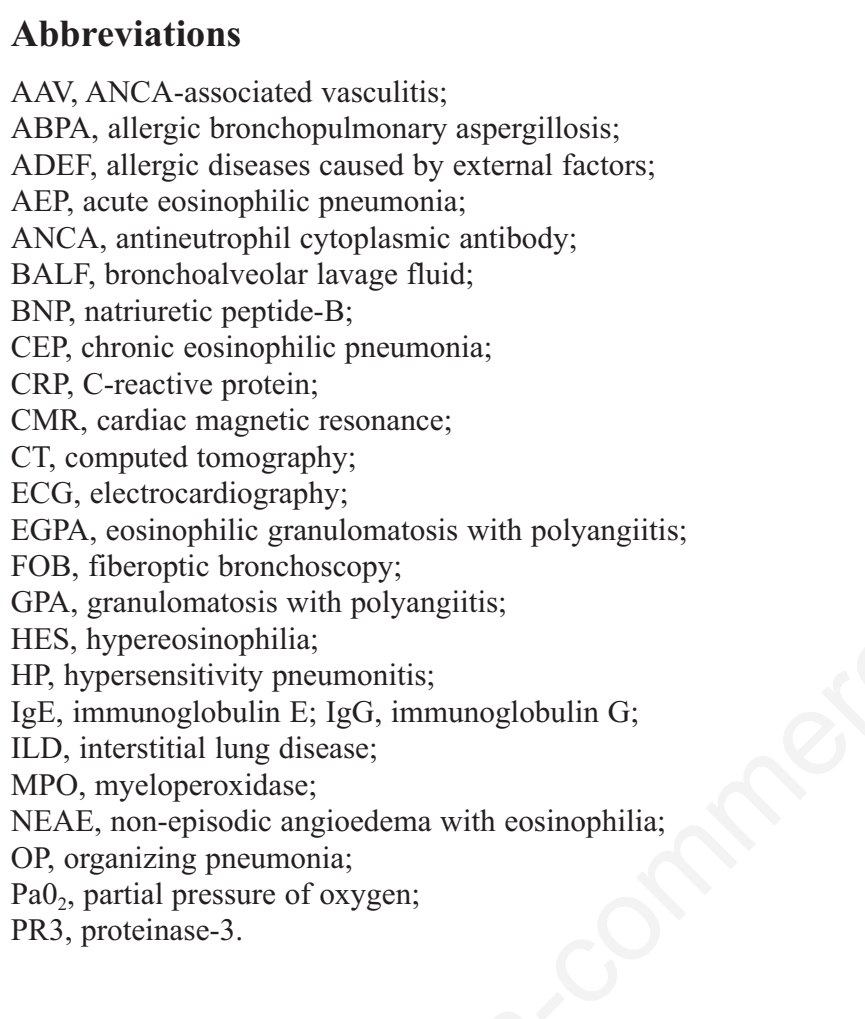

\section{References}

1. Roufosse F. Weller PF. Practical approach to the patients with hypereosinophilia. J Allergy Clin Immunol 2010;126:39-44.

2. Wang SA. The diagnostic work-up of hypereosinophilia. Pathobiology 2019;86:39-52.

3. Wardlaw AJ. Eosinophils in the 1990s: new perspectives on their role in health and disease. Postgrad Med J 1994;70:53652 .

4. Bain BJ, Fletcher SH. Chronic eosinophilic leukemia and the myeloproliferative variant of the hypereosinophilic syndrome. Immunol Allergy Clin North Am 2007;27:377-88.

5. Cottin V. Eosinophilic lung diseases. Clin Chest Med 2016;37:535-56.

6. Simon D, Wardlaw A, Rothenberg ME. Organ-specific eosinophilic disorders of the skin, lung, and gastrointestinal tract. J Allergy Clin Immunol 2010;126:3-13.

7. Bernheim A, McLoud T. A review of clinical and imaging findings in eosinophilic lung diseases. AJR 2017;208:1002-10.

8. Hasegawa K, Stoll SJ, Ahn J, Bittner JC, Camargo CA Jr. Prevalence of eosinophilia in hospitalized patients with asthma exacerbation. Respir Med 2015;109:1230-32.

9. Jin HJ. Biological treatment for severe asthma. Yeungnam Univ J Med 2020;37:262-8.

10. Kim HB, Seo JW, Lee JH, Choi BS, Park SG. Evaluation of the prevalence and clinical impact of toxocariasis in patients with eosinophilia of unknown origin. Korean $\mathrm{J}$ Intern Med 2017;32:523-29.

11. Yoon SY, Baek S, Park SY, Shin B, Kwon HS, Cho YS, et al. Clinical course and treatment outcomes of toxocariasis-related eosinophilic disorder. Medicine 2018;97:37:e12361.

12. Okada R, Nakachi S, Inokuma S. The severity of peripheral blood eosinophilia indicates an eosinophilia-associated disease corresponding to its level. Allergol Int 2016;65:112-4.

13. Sade K, Mysels A, Levo Y, Kivity S. Eosinophilia: a study of 100 hospitalized patients. Eur J Intern Med 2007;18:196-201.

14. Bjerrum OW, Siersma V, Hasselbalch HC, Lind B. Association of the blood eosinophil count with end-organ symptoms. Ann Med Surg 2019;45:11-8.

15. Klion AD, Law MA, Riemenschneider W, et al. Familial eosinophilia: a benign disorder? Blood 2004;103:4050-5.

16. Lombardi C, Passalacqua G. Eosinophilia and diseases: clinical revision of 1862 cases. Arch Intern Med 2003;163:1371-3.

17. Groh M, Pagnoux C, Baldini CV, Bel E, Bottero P, Cottin V, et al. Eosinophilic granulomatosis with polyangiitis (ChurgStrauss) (EGPA). Consensus Task Force recommendations for evaluation and management. Eur J Intern Med 2015;26:54553.

18. Mavrogeni SI, Dimitroulas T, Kitas GD. Cardiovascular magnetic resonance in the diagnosis and management of cardiac and vascular involvement in the systemic vasculitides. Curr Opin Rheumatol 2019;31:16-24.

19. Fijolek J, Wiatr E, Gawryluk D, Nowicka U, MartusewiczBoros MM, Kober J, et al. The significance of cardiac magnetic resonance imaging in detection and monitoring of the treatment efficacy of heart involvement in eosinophilic granulomatosis with polyangiitis patients. Sarcoidosis Vasc Diffuse Lung Dis 2016;33:51-8.

20. Brambatti M, Matassini MV, Adler ED, Klingel K, Camici PG, Ammirati E. Eosinophilic myocarditis. Characteristics, treatment, and outcomes. J Am Coll Cardiol 2017;70:2363-75

21. Boldis V, Ondriska F, Spitalska E, Reiterova K. Immunodiagnostic approaches for the detection of human toxocarosis. Exp Parasitol 2015;59:252-8.

22. Warrel CE, Checkley AM. The investigation of eosinophilia. Medicine 2017;46:30-7

23. Harrold LR, Andrade SE, Go AS, Buist AS, Eisner M, Vollmer WM, al. Incidence of Churg-Strauss syndrome in asthma drug users: a population-based perspective. J Rheumatol 2005;32:1076-80.

24. Nguyen Y, Guillevin L. Eosinophilic granulomatosis with polyangiitis (Churg-Strauss). Semin Respir Crit Care Med 2018;39:471-81.

Received for publication: 30 March 2021. Accepted for publication: 2 September 2021.

This work is licensed under a Creative Commons Attribution-NonCommercial 4.0 International License (CC BY-NC 4.0).

CCopyright: the Author(s), 2021

Licensee PAGEPress, Italy

Multidisciplinary Respiratory Medicine 2021; 16:770

doi:10.4081/mrm.2021.770 